\title{
Most frequent dermatoses at a vulvar pathology outpatient clinic*
}

\author{
Gabriella Cerazi Sartori ${ }^{1}$ \\ Flávia Regina Ferreira ${ }^{3,4}$
}

\author{
Rafaela Tricca Wicher ${ }^{2}$ \\ Valéria Holmo Batista ${ }^{5}$
}

DOI: http://dx.doi.org/10.1590/abd1806-4841.20186784

\begin{abstract}
The vulva corresponds to the external female genitalia. Special features of this region favor a wide range of diseases, whose knowledge allows for better clinical management, impacting on the quality of life. This is a cross-sectional and descriptive study carried out at a vulvar pathology outpatient clinic, between May and December/ 2015. Data obtained from a standard form included demographic parameters, habits, and vulvar dermatosis and allowed to identify the epidemiological profile of patients with vulvar dermatosis treated in this outpatient clinic and to determine the most prevalent dermatoses. Our results, partially concordant with the literature, provide original data that should stimulate further studies
\end{abstract}

Keywords: Epidemiology; Skin diseases; Vulva; Vulvar diseases

The vulva (Latin for sheath) corresponds to the female external genitalia. It has a complex and variable anatomy, but is fundamentally composed by a hymen, anal margin, labia majora and labia minora, and clitoral hood. ${ }^{1,2}$ Folds, humidity and many types of epithelium are present in this region, favoring a wide range of conditions. ${ }^{1,3}$

Vulvar dermatoses (VD) are of common occurrence in clinics and comprehend a heterogenous group of inflammatory (contact dermatitis, lichen sclerosus), malignant (vulvar intraepithelial neoplasia and vulvar Paget's disease) and infectious (candidiasis, herpes simplex and genital wart or condyloma acuminatum) conditions. ${ }^{4,5}$ Vulvar pain, pruritus and dyspareunia are the symptoms that most frequently lead to seeking medical care.

Knowledge on this region and its conditions by gynecologists, dermatologists and genitourinary tract specialists allows for better clinical management, demystification of the subject and, consequently, better quality of life of the patients, since VD have an important impact on self-esteem, emotional and sexual life.
From what was discussed, the objective of this study was to fill a literature gap providing data on the epidemiology of VD in a reference outpatient clinic and also determining the most common dermatoses in this population.

This is a cross-sectional descriptive study performed at the Vulvar Pathology Outpatient Clinic of Hospital Universitário de Taubaté - Taubaté (SP), from May to December/2015. This outpatient clinic is conducted by the Services of Dermatology and Gynecology of the institution.

The studied population comprehended all women attended at this clinic, in the period of the study, with a diagnosis of VD, with no exclusion criteria.

The data were obtained from a standard form, tabulated and analyzed in Microsoft Excel, contemplating demographic parameters and parameters related to the habits and VD.

This study was approved by the Institutional Review Board under the n. ${ }^{\circ} 1.188 .039$.

\footnotetext{
Received on 13.12.2016.

Approved by the Advisory Board and accepted for publication on 14.04.2017.

* Study conducted at Hospital Universitário de Taubaté - Universidade de Taubaté (HUT/-UNITAU) - Taubaté (SP), Brazil.

Financial support: None.

Conflict of interest: None.

Sector of Inter-Hospital Transportation, Núcleo de Atendimento Unimed Tatuapé - São Paulo (SP), Brazil.

Graduation in the Department of Medicine, Universidade de Taubaté (UNITAU) - Taubaté (SP), Brazil.

Discipline of Dermatology, Department of Medicine, Universidade de Taubaté (UNITAU) - Taubaté (SP), Brazil.

Service of Dermatology, Hospital Universitário de Taubaté - Universidade de Taubaté (HUT/-UNITAU) - Taubaté (SP), Brazil.

Discipline of Gynecology and Obstetrics, Department of Medicine, Universidade de Taubaté (UNITAU) - Taubaté (SP), Brazil.
}

MAILING ADDRESS:

Flávia Regina Ferreira

E-mail: dermagica@uol.com.br

C2018 by Anais Brasileiros de Dermatologia 


\begin{tabular}{ll}
\multicolumn{2}{l}{ TABLE 1: Vulvar dermatoses - absolute values and respective } \\
percentages
\end{tabular}

Seventy-five women were included in the study.

Age ranged from 15 to 82 years (mean age of 37 years/sd = 18.7 years). The age group distribution is shown in Graph 1.

Patients were predominantly Caucasian (52 patients - 69.3\%).

Regarding the marital status and schooling, there was an expressive number of single women and with low schooling (up to middle school), 44 (58.7\%) and 40 (53.3\%), respectively.

Defined occupation was reported by 59 women (78.7\%).

Regarding parameters related to sexuality, 70 women (93.3\%) reported active sexual life. Among those, 32 (42.7\%) utilized contraceptive methods, being hormonal contraceptives the most utilized (53.1\%).

Previous history of sexually transmitted diseases (STD) was present in 15 women $(20.0 \%)$, and condyloma acuminatum was the most prevalent STD (11 cases - 73.4\%). Other STDs reported were syphilis and AIDS, eacg with 2 cases (13.3\%).

Mean age for starting sexual activity was 17.3 years ( $\mathrm{sd}=$ $4.3)$, ranging from 12 to 40 years. Of the 75 patients included, 67 $(89.3 \%)$ reported the number of sex partners that ranged from 0 to 14 , with a mean of 2.8 partners $(\mathrm{sd}=2.6)$ per woman.

Comorbidities were reported by 31 patients $(41.3 \%)$, being systemic hypertension the most prevalent (16 cases $-51.6 \%$ ).

The most prevalent VD was condyloma acuminatum (28 cases $-37.3 \%$ ), followed by lichen sclerosus (12 cases $-16.0 \%$ ) (Table 1). Condyloma acuminatum was the most prevalent in younger women (around $93.0 \%$ below 45 years), single (75.0\%) and with up

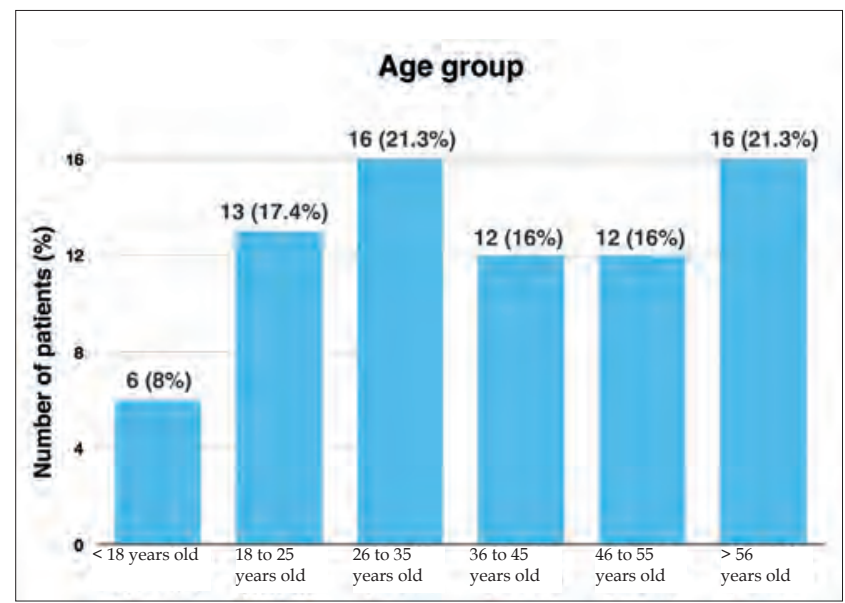

GRAPH 1: Distribution of the patients seen at the vulvar pathology outpatient clinic according to age group

to middle school level (53.6\%). Lichen sclerosus was more prevalent in older age groups $(100.0 \%$ above 35 years, being $75.0 \%$ above 45 years).

Other VD found were: vulvitis $(6.7 \%)$, vulvar intraepithelial neoplasia $(6.7 \%)$, candidiasis $(5.3 \%)$, molluscum contagiosum (4.0\%), vulvar granuloma $(4.0 \%)$, Bartholin cyst $(4.0 \%)$, perineal abscess $(2.7 \%)$, seborrheic keratosis $(2.7 \%)$, vitiligo $(2.7 \%)$, contact dermatitis $(2.7 \%)$, neurodermitis $(1.3 \%)$, hidradenitis $(1.3 \%)$, cysts (1.3\%) and pityriasis versicolor (1.3\%) (Table 1$)$.

This is a pioneer study on this subject that allowed for the identification of the epidemiological profile of VD patients seen in this reference outpatient clinic and for the determination of the most prevalent dermatoses in this population, providing original data and motivating future studies.

The comparative analysis of the epidemiological profile becomes difficult in view of the lack of data from clinics with the same characteristics, in general, studies from gynecology or general dermatology clinics, and also population-based and non-hospital-based studies.

The most prevalent VD is a controversy in the literature. ${ }^{6-8}$ This discrepancy is possibly due to the diversity of the source of data. The predominance of condyloma acuminatum was in agreement with the findings by Carvalho and Queiroz $^{8}$ but differed from the findings by Virgili et al. ${ }^{6}$ and Farias et al. ${ }^{7}$ The age group, marital status and schooling levels found for this condition in this population is in accordance to the literature. ${ }^{8,9}$

Lichen sclerosus, the second most prevalent in this sample, has a bimodal distribution: pre-pubertal children and women with more advanced age. ${ }^{6}$ Thus, the findings of this study support the literature regarding its occurrence in older age groups.

The limitations of this study are its short period of recruitment, small sample and its hospital-based nature. Therefore, care is advised in the external extrapolation of the findings. $\square$ 


\section{REFERENCES}

1. Barchino-Ortiz L, Suárez-Fernández R, Lázaro-Ochaita P. Vulvar Inflammatory Dermatoses. Actas Dermosifiliogr. 2012;103:260-75

2. Doyen J, Demoulin S, Delbecque K, Goffin F, Kridelka F, Delvenne P. Vulvar Skin Disorders throughout Lifetime: About Some Representative Dermatoses. Biomed Res Int. 2014;2014:595286

3. Tavares E, Martins C, Teixeira J. Dermatoses Vulvares Inflamatórias. Rev Soc Port Dermatol Venereol. 2011;69:561-71.

4. Colposcopia.org.[Intenet]. Parellada Cl, Campaner AB, Bovo A. Classificações da Vulva. ABPTGIC - Associação Brasileira de Patologia do Trato Genital Inferior e Colposcopia. [s.d.] [citado 2015 Jun 10]. Disponível em: http://colposcopia.org. br/files/CLASSIFICACOES-DA-VULVA-para-homepage.pdf

5. $\quad$ Peckruhn M, Elsner P. Vulvar Diseases. Hautarzt. 2015;66:38-4.

6. Virgili A, Borghi A, Toni G, Minghetti S, Corazza M. Prospective clinical and epidemiologic study of vulvar lichen sclerosus: analysis of prevalence and severity of clinical features, together with historical and demographic associations. Dermatology. 2014;228:145-51.
7. Farias IA, Cavalcanti e Silva DGK. Estudo da prevalência de doenças sexualmente transmissiveis entre mulheres em idade fértil atendidas em Estratégia de Saúde da Família de Acari/RN. Biota Amazônia. 2015:5:1-6.

8. Carvalho MC, Queiroz AB. Mulheres Portadoras de Lesões Precursoras do Câncer do Colo do Útero e HPV: Descrição do Perfil Socioeconômico e Demográfico. DST J Bras Doenças Sex Transm. 2011;23:28-33.

9. Trujillo IA, López PA, Pérez DC, Barbeito TO, Pavón YH, Pérez MP. Caracterización clínica, epidemiológica y terapêutica de pacientes con condiloma acuminado. Dermatol PERU. 2014;24:80-8.

How to cite this article: Sartori GC, Wicher RT, Ferreira FR, Batista VH. Most frequent dermatoses at a vulvar pathology outpatient clinic. An Bras Dermatol. 2018;93(2):294-6. 